\title{
A PERSPECTIVA DE PARTICIPAÇÃO E DE AUTONOMIA DOS CONSELHOS MUNICIPAIS DE EDUCAÇÃO EM GOIÁS
}

\author{
Dra . Elizabeth Gottschalg Raimann \\ Me. Renata Freitas Dias \\ Esp. Fátima Almeida Baraúna \\ Universidade Federal de Goiás/ Regional Jataî
}

\begin{abstract}
RESUMO: O artigo objetiva analisar as perspectivas de participação dos Conselhos Municipais de Educação (CME), bem como a autonomia que possuem no processo decisório de suas ações. Os municípios pesquisados no estado de Goiás foram Jataí, Mineiros, Rio Verde, Itumbiara, Anápolis e Goianésia, sendo encaminhado aos conselhos, por meio de correio eletrônico (e.mail), um questionário com perguntas abertas e fechadas. A partir da devolutiva das questões, foram analisadas as categorias participação e autonomia. Os dados evidenciaram quanto à participação dos
\end{abstract}

membros conselheiros no processo decisório do Conselho Municipal de Educação que esta pode ser caracterizada com maior ênfase pela natureza consultiva. Considerando a forma de composição do colegiado nos diversos conselhos, no que tange o aspecto da autonomia dos conselheiros, esta se encontra comprometida, pois os membros, em sua grande parte, estão vinculados ao executivo municipal. Diante disso, pode-se afirmar que a participação e autonomia dos conselheiros está fragilizada diante de uma gestão democrática.

PALAVRAS-CHAVE: Conselho Municipal de Educação; Participação; Autonomia.

\section{THE PARTICIPATION AND AUTONOMY PERSPECTIVE OF MUNICIPAL COUNCILS OF EDUCATION IN THE STATE OF GOIÁS}

\begin{abstract}
The article aims to analyze the perspectives of the participation of the Municipal Councils of Education, as well as the autonomy that they hold in the decision-making process of their actions. The researched municipalities in the State of Goiás were Jataí, Mineiros, Rio Verde, Itumbiara, Anápolis and Goianésia. A questionnaire with open and closed questions was sent to the councils by electronic mail (e-mail). Participation and autonomy categories were analyzed based on the answers to the questions. Regarding the participation of the
\end{abstract}

council members in the decision-making process of the Municipal Council of Education, data evidenced that this can be characterized with a higher emphasis of the consultative nature. Considering the composition of the collegiate in the various councils, in regards to the autonomy of the councilors, this one is found compromised, since its members, in the majority, are connected to the municipal executive. Given this, it can be inferred that the participation and autonomy of the councilors is weakened, considering the democratic management.

KEYWORDS: Municipal Council of Education; Participation; Autonomy. 


\section{Educere "Educare \\ ReVISTA DE EduCACÃo}

Programa de Pós-Graduação em Educação - Universidade Estadual do Oeste do Paraná

\section{INTRODUÇÃO}

No contexto brasileiro, o Conselho Municipal de Educação (CME), em sua constituição histórica, encontra-se desvirtuado daquilo que realmente deveria ser como exercício da representatividade social. Sua fundante função deveria ser a de um elo entre população e governo, ou seja, caixa de ressonância das expectativas da comunidade escolar, com o propósito de aproximar a população das políticas públicas educacionais, a fim de tornar as medidas educativas reais às necessidades sociais existentes, num processo realmente democrático.

Para que o conselho seja democrático não basta apenas criar o colegiado e ter o espaço de reuniões, é preciso que seus integrantes tenham vez e voz participativa de fato, nas decisões da política educacional local. Garantir a democratização educacional é, antes de qualquer coisa, garantir a participação das pessoas no processo e respeitá-las como sujeitos sociais. É autovalorizar a expressão de pensamento, mas também oportunizar a expansão da reflexão individual, numa dimensão ontológica do gênero humano.

Nesse sentido, a contradição no ambiente de discussão do CME é condição para a tomada de decisões. Cada segmento representado se coloca na discussão, oportunizando diferentes pontos de vista. Por isso, a exigibilidade da heterogenia do grupo é essencial para que haja pensamentos e culturas diferentes se posicionando na tomada de decisões.

Objetivando analisar as perspectivas de participação dos Conselhos Municipais de Educação ( $\mathrm{CME}$ ) em seis cidades do Estado de Goiás, bem como a autonomia que possuem no processo decisório de suas ações, apresenta-se, no primeiro momento, a metodologia da pesquisa. Após, as categorias participação e autonomia serão discutidas mediante referencial teórico. E, na sequência, a discussão e análise dos dados referentes aos conselhos, como contexto de criação, a forma de composição, a quantidade de membros e a principal função que exercem.

Revista Educere Et Educare, Vol. 13, N. 27, jan./abr. 2018. Ahead of Print. DOI: 10.17648/educare.v13i27.17918 


\section{Educere "Educare \\ RevISTA de EduCACÃo}

Programa de Pós-Graduação em Educação - Universidade Estadual do Oeste do Paraná

Em função da complexidade do tema, acredita-se que o processo de conhecimento está em construção e o incentivo de se pesquisar sobre o CME tem sua relevância, considerando os aspectos da participação social na busca da qualidade da educação socialmente referenciada.

\section{METODOLOGIA}

No intuito de investigar em que medida ocorre a participação dos representantes do $\mathrm{CME}$ no estado de Goiás nas deliberações deste conselho, realizou-se um levantamento de dados de seis Conselhos Municipais de Educação (CME) no Estado de Goiás, sendo eles: Anápolis, Goianésia, Itumbiara, Jataí, Mineiros e Rio Verde. Esta pesquisa insere-se numa problemática mais ampla de um estudo desenvolvido no bojo das ações do projeto de pesquisa "O Conselho Municipal de Educação em Goiás e a qualidade socialmente referenciada do ensino" que, por sua vez, busca analisar se as ações do CME no Brasil têm contribuído para a qualidade socialmente referenciada do ensino, vinculada a uma pesquisa interinstitucional sobre os Conselhos Municipais de Educação no Brasil envolvendo cinco instituições públicas, Universidade Federal de Uberlândia, Universidade Federal Grande Dourados, Universidade Federal de Mato Grosso, Universidade Federal de Goiás/ Regional Jataí e Universidade Estadual de Mato Grosso.

A escolha dos conselhos pesquisados em Goiás ocorreu a partir da entrega de questionários aos conselheiros que participaram de dois encontros: I Encontro dos CME - região sudeste I - pólo Jataí e o X Encontro dos CME do estado de Goiás. O questionário foi estruturado com perguntas fechadas e abertas, as respostas, no total de 64, foram devolvidas por escrito ou via e-mail. Destes, foram selecionados os conselhos que tinham documentos disponiveis na web, tanto no portal da Secretaria Municipal de Educação quanto na prefeitura de cada cidade, ou ainda em algum blog específico para o acesso a documentos produzidos como resoluções, pareceres, oficios, encaminhamentos, dentre outros. 


\section{Educere "Educare \\ RevISTA DE Educacão}

Programa de Pós-Graduação em Educação - Universidade Estadual do Oeste do Paraná

Para este artigo, as categorias de análise escolhidas foram autonomia e participação, cujo referencial teórico de análise fundamenta-se a partir das contribuições de Bordenave (1983), Bordignon (2009), Lima (2001; 2010; 2015) e Motta (1987).

\section{RESULTADOS E DISCUSSÕES}

\subsection{Participação e autonomia: o que significa isso?}

A participação promove a ascensão da classe popular no âmbito político, no sentido de gerar discussões e conflitos que resultem na formação de opiniões e ações junto ao CME. A sociedade participativa é uma proposta que pode ser construída, levando-se em consideração o processo histórico-cultural de constituição da sociedade local. No entanto, para elevar a consciência social e política das pessoas é necessário espírito de luta para enfrentar o controle e a imposição do Estado, já que este possui um conceito de participação voltado à visão neoliberal.

Segundo a avaliação de Bordenave (1983), "quando o governo controla a participação do povo, mas não é controlado pelo povo, é sinal de que ainda falta muito tempo para se chegar à sociedade participativa. Nesta, o povo exerce o controle final das decisões dos níveis mais elevados" (p.36). Diante disso, o CME deveria representar a vontade do povo, por isso é tão forte o elemento da participação nas decisões advindas do poder público. Participar significa corresponder à vontade da maioria que, muitas vezes, não tem voz no processo democrático.

Defende-se que a participação pressupõe autonomia tanto intelectual quanto material do CME. Ou seja, que o colegiado tenha a liberdade de expressar pensamentos, opiniões e anseios, ter o direito ao espaço físico independente, recursos materiais para exercer as funções de conselho. Para Bordignon (2009), "Com a participação democrática e a vontade política cada município encontrará o caminho mais adequado a sua realidade" (p.77). Diante dessa perspectiva, faz- 


\section{Educere "Educare \\ Revista de Educacẽo}

Programa de Pós-Graduação em Educação - Universidade Estadual do Oeste do Paraná

se essencial o papel dos conselheiros enquanto mediadores na tomada de decisões. E as políticas públicas educacionais deverão encontrar um meio termo entre o que o povo anseia por qualidade da educação e o que o executivo entende por qualidade da educação para que haja uma ponderação, um equilíbrio entre a vontade do povo e a vontade governamental.

O autor acima ainda expõe que a participação não é apenas um bonito desejo baseado no princípio da democratização das decisões, mas uma necessidade essencial para que, ao balizar as politicas educacionais, não só atendam as vontades do mercado, mas também o mínimo das necessidades sociais existentes.

Para que ocorram movimentos no sentido de democratização da educação, o espaço de participação nos conselhos deve respeitar o tempo necessário para que os membros possam discutir e debater temas de conflito, considerar a diversidade de opiniões e assim seguir para a tomada de decisão numa perspectiva participativa.

Motta (1987), ao tratar da temática participação e administração no contexto da educação, discute a relação de poder em seus aspectos de exploração e opressão, apontando para a possibilidade de minimizar o papel coercitivo da administração mediante a participação. Esclarece que participar "não significa assumir um poder, mas participar de um poder" (MOTTA, 1987, p.91) e, ao mesmo tempo, tenciona o que seja a participação. De acordo com o autor, "é perfeitamente possivel a coletividade influir sobre o poder, ao mesmo tempo em que este procura cooptá-las para seus objetivos" (ibid, p.91). Isso aponta para o aspecto de tensões permanentes quando um conselho de fato é representativo de cada segmento, pois, nesse caso, seus representantes não são levados a ter um pensamento único, mas de fato a se posicionam de maneira crítica $\mathrm{e}$ participativa.

Bordenave (1983), por sua vez, ao tratar da participação, aponta para uma base afetiva e outra instrumental. Sendo que na primeira, participa-se por prazer 


\section{Educere "Educare \\ ReVISTA DE EduCAC̄̃o}

Programa de Pós-Graduação em Educação - Universidade Estadual do Oeste do Paraná

de estar junto e na segunda, pela eficácia e eficiência da ação de participar no coletivo.

Motta (1987) apresenta tipos de participação, sendo elas: participação conflitual, participação funcional, participação administrativa, cogestão e autogestão. Explicita cada uma delas e esclarece que, na educação, a participação administrativa é a mais usual, pois "é um tipo especial de participação, que se organiza por representação [...] formação de comissões [...] que reúnem [...] administradores, funcionários e trabalhadores” (p. 92).

Esse tipo de participação acima se assemelha bastante com o critério de composição do CME nos municípios goianos que elegem seus representantes por categoria de representatividade.

Considerando o desafio da administração para uma participação efetiva, Motta afirma

Aos administradores educacionais cabe especialmente o desafio não pequeno de descobrir e delinear formatos organizacionais que, adequados a contextos específicos, assegurem a educação participativa voltada para a construção de uma sociedade verdadeiramente igualitária, não apenas em termos econômicos, mas em termos de distribuição do poder. (1987, p. 94).

Este desafio também deve ser assumido pelo CME e se posicionar de forma crítica interferindo na realidade educacional, propondo mudanças, conforme a necessidade da comunidade. A ideia é favorecer o aspecto democrático dessa participação, já que a maioria das pessoas tem uma concepção muito ingênua, confundindo participação com participacionismo. Sobre este conceito, Lima esclarece:

São ações restritas a um participacionismo que implica: eleições de diretores limitadas a indicações; formação de conselhos municipais de educação tutelados; conselhos de classe meritocráticos em que o que mais importa são disciplina, controle e visão moralizante. (2015, p. 79).

Bordignon (2009) ainda relembra que autonomia não está apenas no plano intelectual (na vontade e na liberdade de pensamento), mas também no plano 


\section{Educere "Educare \\ RevISTA de EduCACÃo}

Programa de Pós-Graduação em Educação - Universidade Estadual do Oeste do Paraná

material, pois, segundo ele, esse interfere, especialmente, na estrutura de funcionamento do conselho, como se lê:

No campo da autonomia é necessário destacar a importância de dotação orçamentária própria para os conselhos. Por outro lado, as condições precárias de funcionamento afetam a qualidade do exercício das nobres e relevantes funções atribuídas aos conselhos municipais de educação. (2009, p. 84).

Outro aspecto importante nas ponderações do autor acima é o fato dos conselhos terem seus membros por indicação do chefe do executivo, pois sua autonomia fica limitada e condicionada aos seus interesses. Outra questão é o fato do conselho funcionar em salas localizadas no prédio da secretaria municipal de educação, o que, sem dúvida, compromete o aspecto da autonomia desse órgão. Na verdade, cria-se uma espécie de cumplicidade, reforçando o papel paternalista e controlador do Estado.

Contudo, mesmo diante da problemática acerca do tipo de participação dentro do $\mathrm{CME}$, existe uma relevância que não se pode negar quanto às vivências que os conselheiros adquirem ao participarem de reuniões, debates, eventos e fóruns em um espaço público, isso pode contribuir para a sua formação política e a possibilidade de um espírito crítico. Teixeira ao refletir nas potencialidades dos espaços públicos afirma, "Nesta perspectiva, ao lado dos conselhos, considera-se a importância de fóruns, plataformas, conferências que, embora tendo relacionamento e interlocução com o poder político, constituem espaços públicos autônomos"(2004, p.707).

Para tanto, é preciso que a sociedade em geral entenda que apesar do CME ser uma instância institucionalizada, tem a potencialidade em representar os setores populares e que deveria servir de espaço para a expressão das necessidades sociais locais por meio da participação e autonomia de seus conselheiros. A propósito dos conselhos, em seu processo de reformulação, Basílio afirma 


\section{Educere "Educare \\ RevISTA de EduCACÃo}

Programa de Pós-Graduação em Educação - Universidade Estadual do Oeste do Paraná

São um caminho importante para pressionar o Governo na garantia do acesso de todos a bens públicos de qualidade para um país mais democrático. No entanto, para fazer desse espaço um lugar que atenda às necessidades locais, é preciso ecoar as múltiplas vozes até então pouco ouvidas pelo sistema centralizador. (2012, p.16).

Conforme se verifica nesta pesquisa, a simples existência do CME e da lei que o institucionaliza não garante a democracia em seu interior. As ações democráticas são percebidas pelos níveis de participação e liberdade de poder de decisão desse órgão. Os membros do conselho são pessoas da sociedade civil que possuem responsabilidade de decidir pelos demais, por isso o papel dessas pessoas vai além da formalidade, pois é necessário acompanhar, fiscalizar e mobilizar a sociedade para participar das políticas educacionais.

\subsection{O funcionamento do CME: criação, composição e função}

Ao se analisar as respostas do questionário proposto aos conselheiros dos municipios goianos, priorizou-se a análise das categorias autonomia e participação do $\mathrm{CME}$, envolvendo seis cidades: Anápolis, Goianésia, Itumbiara, Jataí, Mineiros e Rio Verde.

Dentre várias questões respondidas, o objeto de análise foram os dados referentes à data de criação do $\mathrm{CME}$, à sua forma de composição, à quantidade de membros e à principal função do conselho. O início de funcionamento dos conselhos ocorre em três momentos distintos, ou seja, quando a legislação federal e estadual será a mola propulsora da criação dos CME no estado, tendo como pano de fundo o financiamento da educação e o salário-educação. O quadro abaixo sistematiza os dados, com as datas de criação do CME nestes municípios.

Quadro 1- Ano de criação do CME

\begin{tabular}{|l|c|l|l|l|c|}
\hline \multicolumn{2}{|c|}{1997} & \multicolumn{2}{c|}{2001} & 2009 \\
\hline Rio Verde & Mineiros & Jataí & Anápolis & Itumbiara & Goianésia \\
\hline
\end{tabular}

Fonte: Questionário grupo de pesquisa sobre CME/ UFG Regional de Jataí. 


\section{Educere "Educare \\ RevISTA de EduCACÃo}

Programa de Pós-Graduação em Educação - Universidade Estadual do Oeste do Paraná

Pode-se verificar que, das principais cidades que compõem o sudoeste goiano, Rio Verde, Mineiros e Jataí estas tiveram seus conselhos iniciados no ano de 1997. Cidades como Anápolis e Itumbiara, por sua vez, em 2001 e Goianésia somente em 2009.

No sudoeste goiano, as cidades em destaque criaram seus conselhos em conformidade com a Lei de Diretrizes e Bases da Educação n. ${ }^{\circ}$ 9.394/1996 e a Lei complementar n. ${ }^{\circ}$ 26/1998 referente às Diretrizes e Bases do Sistema Educacional de Goiás, além do Fundo de Manutenção e Desenvolvimento do Ensino Fundamental e de Valorização do Magistério (FUNDEF), instituído pela Emenda Constitucional n. ${ }^{\circ}$ 14, de setembro de 1996 (ALVES, 2014). É perceptível que a municipalização e a disputa por financiamento da educação motivaram a criação dos conselhos nestes municípios. Naquele momento, a criação do CME de Goiânia, também no ano de 1997, de acordo com a Lei Municipal n. ${ }^{\circ}$ 7.771, serviu de referência aos demais municipios goianos (ALVES, 2011).

Os conselhos de Anápolis e Itumbiara, por sua vez, foram criados no momento em que o Estado de Goiás aprovou a Lei no 13.609 em 2000, ao regulamentar a redistribuição dos salários-educação pelo governo estadual nos municípios (ALVES, 2014). E o CME de Goianésia, criado em 2009, teve como estímulo o Plano Estadual de Educação (2008-2017).

A década de 1990 foi fortemente marcada pelas propostas de mudanças nas politicas públicas educacionais a partir dos preceitos constitucionais na Carta Magna de 1988, pois nesse momento falava-se de princípios democráticos e de padrão de qualidade previsto no art. 206, inc. VI e VII. Nesse mesmo contexto, surgiu a descentralização administrativa do ensino em seu art. 211. Apesar da Constituição Federal não fazer menção aos conselhos de educação, implicitamente vincula sua relação à organização dos sistemas de ensino. A partir de então, fortaleceu a concepção de colegiados com a expectativa de que os conselhos de educação seriam mais representativos (TEIXEIRA, 2004). 


\section{Educere "Educare \\ RevISTA DE Educacão}

Programa de Pós-Graduação em Educação - Universidade Estadual do Oeste do Paraná

Na segunda metade da década de 1990, grande parte dos municípios optou por instituírem seus sistemas de ensino, tomando como base a concepção neoliberal do Estado de descentralização. Apesar do vocábulo descentralização não ser sinônimo de municipalização, estas palavras relacionam-se pela ideia clientelista do governo que, segundo Lima (2001), gerou-se uma "desconcentração" ao invés de descentralização. Isso aconteceu devido ao repasse de responsabilidades aos municípios, sem amparo necessário à gestão, uma vez que a verdadeira descentralização daria a autonomia de fato aos municípios. Desta forma, não caberia ao órgão federal a tomada de decisão unilateral e de cima para baixo. O repasse de verbas públicas seria o mínimo para garantir a autogestão administrativo-pedagógica.

Nesse contexto, muitos municípios acreditaram que poderiam ter autonomia e criaram seus sistemas municipais de ensino e, ao mesmo tempo, instituíram o CME. Teixeira (2004), em sua pesquisa realizada com municípios do Triângulo Mineiro, observou que existia um número pequeno de municípios que possuíam CME antes de 1980, por isso não tiveram nenhuma relação com a municipalização.

$\mathrm{Na}$ pesquisa em tela, dos seis municípios pesquisados, apenas um coincide a data da criação do sistema de ensino do seu município com o CME. Rio Verde criou seu conselho no mesmo dia em que implantou o SIMERV (Sistema Municipal de Ensino de Rio Verde), na data de 14/05/1997.

O município de Jataí criou seu CME em 2009, um ano antes do sistema municipal, instituído em 2010. Os municípios de Itumbiara e Anápolis, por sua vez, criaram seu CME em 2001, sendo que Itumbiara teve seu sistema de ensino instituído em 1983, bem antes da criação do CME. Já o município de Anápolis implantou seu sistema de ensino no ano de 2000. E o município de Mineiros teve seu CME implantado em 1997, três anos antes do sistema municipal de ensino que ocorreu em 2010. O município de Goianésia criou o CME em 2009 e seu sistema de ensino foi instituído, posteriormente, em 2010. Certamente, os 


\section{Educere "Educare \\ RevISTA DE Educacão}

Programa de Pós-Graduação em Educação - Universidade Estadual do Oeste do Paraná

municípios que instituíram sistema municipal de ensino posterior à data de criação do $\mathrm{CME}$ ficaram vinculados à Secretaria Estadual de Educação, até estabelecerem seus próprios sistemas.

Bordignon (2009) lembra que a lei federal não expressa a criação de conselhos municipais de educação, pois a decisão de criar o conselho é exclusiva do município. Todavia, mesmo sem determinação legal, os municípios sentiram a necessidade da criação do CME. Infere-se que seja pelo fato da relação de dependência entre $\mathrm{CME}$ e o recebimento de recursos financeiros Assim, $\mathrm{O}$ município que mais se apressou na municipalização quanto à instituição do sistema de ensino foi o município de Rio Verde. Isso é um demonstrativo de que o interesse econômico se sobrepôs ao interesse social, nesse período.

O autor ainda ressalta que "cada município, de acordo com sua singularidade de sua realidade, especialmente do seu sistema de ensino, encontrará a organização mais adequada para o desempenho de suas funções" (BORDIGNON, 2009, p. 73).

Nesse sentido, a composição dos conselhos, em seu processo de autonomia, indica que a representatividade da pluralidade social pode significar a diversidade das categorias existentes no município e gerar o equilíbrio. Porém, é importante levar em consideração que o CME de um determinado local não terá uma atuação semelhante a outro, levando em consideração o fato de que cada conselho possui sua singularidade, particularidade e sua identidade (LIMA, 2010).

O gráfico a seguir ilustra a composição dos conselhos. 


\section{Educere Educare \\ REVISTA DE EdUCACÃO}

Programa de Pós-Graduação em Educação - Universidade Estadual do Oeste do Paraná

Gráfico 1- Forma de composição do CME

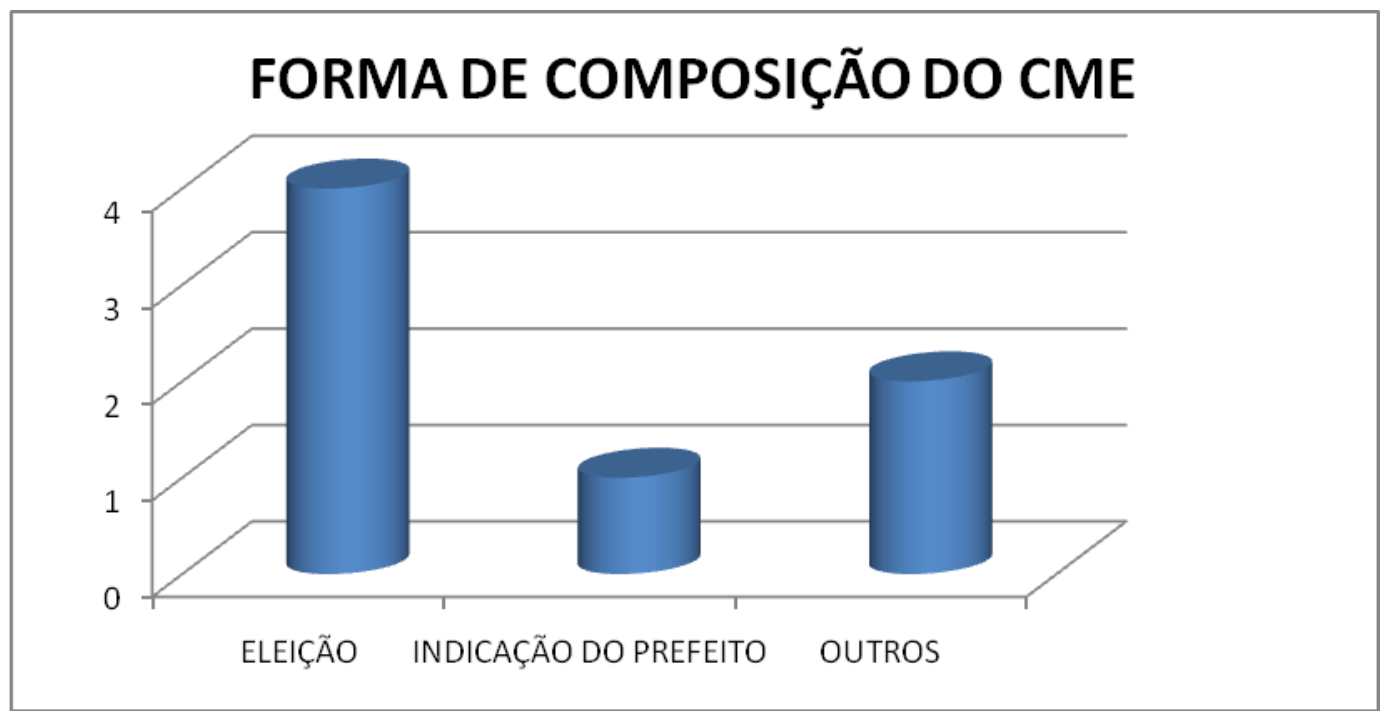

Fonte: Questionário grupo de pesquisa sobre CME/ UFG Regional de Jataí.

Os dados apresentados elucidam de que forma os representantes do CME dos municípios são escolhidos. Verifica-se que, dentre seis municípios, três, sendo eles Rio Verde, Anápolis e Jataí, indicam que é por eleição. Os municípios de Mineiros e Itumbiara afirmam ser por outros meios. E apenas o município de Goianésia aponta para a indicação do prefeito. Vale ressaltar que a resposta "outro" é uma das opções dentro das alternativas: eleição, indicação do prefeito, outros.

A princípio, os municípios em análise apresentam o processo de participação pela constituição do $\mathrm{CME}$, mas ainda não se pode afirmar que na sua concretude isso aconteça, podendo ser apenas uma participação formal, já que o modo de composição num viés democrático não significa que a forma de composição foi democrática. Pode ser apenas uma proposta de participacionismo, ainda que "o Estado afirme a autonomia dos entes federados, o que se realiza são experiências que não têm avançado na construção da Gestão Democrática". (RAIMANN, 2015, p.79). 


\section{Educere Educare \\ RevISTA DE Educacão}

Programa de Pós-Graduação em Educação - Universidade Estadual do Oeste do Paraná

A forma de composição do $\mathrm{CME}$ desses municípios varia entre a indicação do prefeito e o processo eleitoral. Nesse sentido, o que se percebe é uma eleição por representação de categoria, ou seja, indicação de classes. Os municípios de Itumbiara e Mineiros, que responderam no questionário a opção "outro", não especificaram como acontece o processo.

Tendo acesso ao regimento do CME de Rio Verde pode-se perceber que em Rio Verde o processo de eleição se compromete pela parcialidade, pois o chefe do executivo é que escolhe os conselheiros, tomando como base os nomes indicados pela categoria. Nesse sentido, Lima afirma:

[...] a participação de alguns conselheiros parece ser motivada por, realmente, um sentimento afetivo com o intuito de intervir ativamente na construção da sociedade. Esses, geralmente, dão suas contribuições para os debates, são bem falantes, críticos e questionadores. Mas, também, existem alguns conselheiros que estão limitados, pois, como representantes do Poder Executivo, contribuem para a limitação do Conselho. (2010, p. 42).

Sendo assim, pode-se inferir que quando a escolha do prefeito não possui critérios claros, os membros escolhidos não vão assumir o compromisso com o povo, mas sim com quem o escolheu.

Teixeira (2004) explica que apesar da representatividade por categoria ser melhor que a indicação direta pelo chefe do executivo e ainda superar as escolhas personalistas e clientelistas, é provável que essa representação se torne cooperativa na defesa de interesse do grupo ao qual pertence.

Lima (2010), por sua vez, levanta a seguinte questão: indicação por categoria, em que os representantes são selecionados por meio de conversas, de fato, não produz o processo democrático. Segundo o pensamento do autor, o que garante a democracia popular é a eleição pelo voto. Nessa representação por categoria, são levados em conta os círculos de amizade, de confiança, de subordinação, dentre outros vínculos.

Outra questão fundamental é o numero de membros do conselho. Na concepção de Bordignon (2009), para uma melhor efetivação da participação dos 


\section{Educere "Educare \\ ReVISTA DE EduCACÃo}

Programa de Pós-Graduação em Educação - Universidade Estadual do Oeste do Paraná

membros do conselho, o número de composição não pode ser muito pequeno, uma vez que dificulta e limita o diálogo entre os pares.

No questionário respondido pelos conselheiros, no que se refere ao número de membros na composição do $\mathrm{CME}$, verificou-se que o número fica entre seis e quinze integrantes, sendo que nenhum deles possui mais de quinze membros. Conforme se pode ver no quadro abaixo.

Quadro 2- Números de membros do CME

\begin{tabular}{|c|c|}
\hline Município & $\mathrm{N}^{\circ}$ de membros \\
\hline Mineiros & 6 a 10 \\
\hline Anápolis & 11 a 15 \\
\hline Goianésia & 6 a 10 \\
\hline Jataí & 15 \\
\hline Rio Verde & 11 a 15 \\
\hline Itumbiara & \\
\hline
\end{tabular}

Fonte: Questionário grupo de pesquisa sobre CME/ UFG Regional de Jataí.

Os conselheiros que compõem o CME de Mineiros e Jataí são entre 6 a 10 membros, em Anápolis e Itumbiara entre 11 a 15 membros, Goianésia entre 11 a 15 membros e, por fim, o município de Rio Verde, não tem quantitativo mínimo apenas o máximo de 15 membros. Essa representação é definida por Motta (1987) como sendo uma participação administrativa "um tipo especial de participação, que se organiza por representação" (p. 92).

Observa-se que participação é o meio de minimizar a coerção provocada pela administração, mas essa participação, mencionada por Motta (1987), deve ser autêntica e não um processo de camuflagem do sistema. 


\section{Educere Educare \\ RevISTA DE Educacão}

Programa de Pós-Graduação em Educação - Universidade Estadual do Oeste do Paraná

Bordignon (2009) reconhece três aspectos relevantes para a definição do número de conselheiros: o tamanho do Sistema Municipal de Ensino, o equilíbrio das categorias a serem representadas no conselho e a duração dos mandatos.

Outro elemento em destaque refere-se à principal função que exerce o $\mathrm{CME}$, a compreensão sobre o papel dos membros, isto é de suma importância para direcionar as ações a serem desenvolvidas.

Na perspectiva de Bordignon (2009), o CME tem como principais funções deliberativa, consultiva e, no contexto atual, a função mobilizadora e a de controle social. Para o autor, a natureza da função significa a competência conferida ao conselho.

Ainda de acordo com Bordignon (2009), o caráter deliberativo refere-se à decisão final em matérias específicas por meio de instrumentos próprios. Nessa função, o conselho aprova, decide, estabelece normas e ações, não tendo nenhuma interferência do poder executivo. O caráter consultivo está no plano de assessoramento às ações do Governo na matéria educacional. Este funciona como um colaborador na formulação das políticas públicas, sendo que no seu exercício opina, responde a consultas, propõe ações sobre temas relevantes por meio de pareceres.

O mais novo conceito que propõe, no viés democrático, é o caráter mobilizador e de controle social. Originário do anseio social, o desejo de participação democrática na formulação e gestão das políticas públicas, contribui para que os conselhos assumam esta nova função. Esta faz parte do campo propositivo, de acompanhamento e controle na oferta de serviços educacionais. Além de acompanhar ações voltadas à qualidade da educação, deve também promover eventos, conferências, audiências públicas, a fim de subsidiar suas decisões, envolvendo assuntos relevantes sobre seu município.

Quanto ao questionamento sobre as funções que o CME exerce, os respondentes deveriam optar pelas seguintes opções: deliberativo, consultivo, 


\section{Educere Educare \\ RevISTA De EduCAC̄̃o}

Programa de Pós-Graduação em Educação - Universidade Estadual do Oeste do Paraná

informativo, fiscalizador, burocrático, pedagógico, propositivo, mobilizador ou outro.

As respostas estão representadas no gráfico 2 abaixo. Assim, dois conselheiros responderam que a principal função do seu CME é deliberativo; um afirmou ser consultivo; dois afirmaram ser consultivo, deliberativo e propositivo. Um conselheiro marcou a opção outra função, explicando ser a qualidade da educação.

Gráfico 2 - Principal função do CME

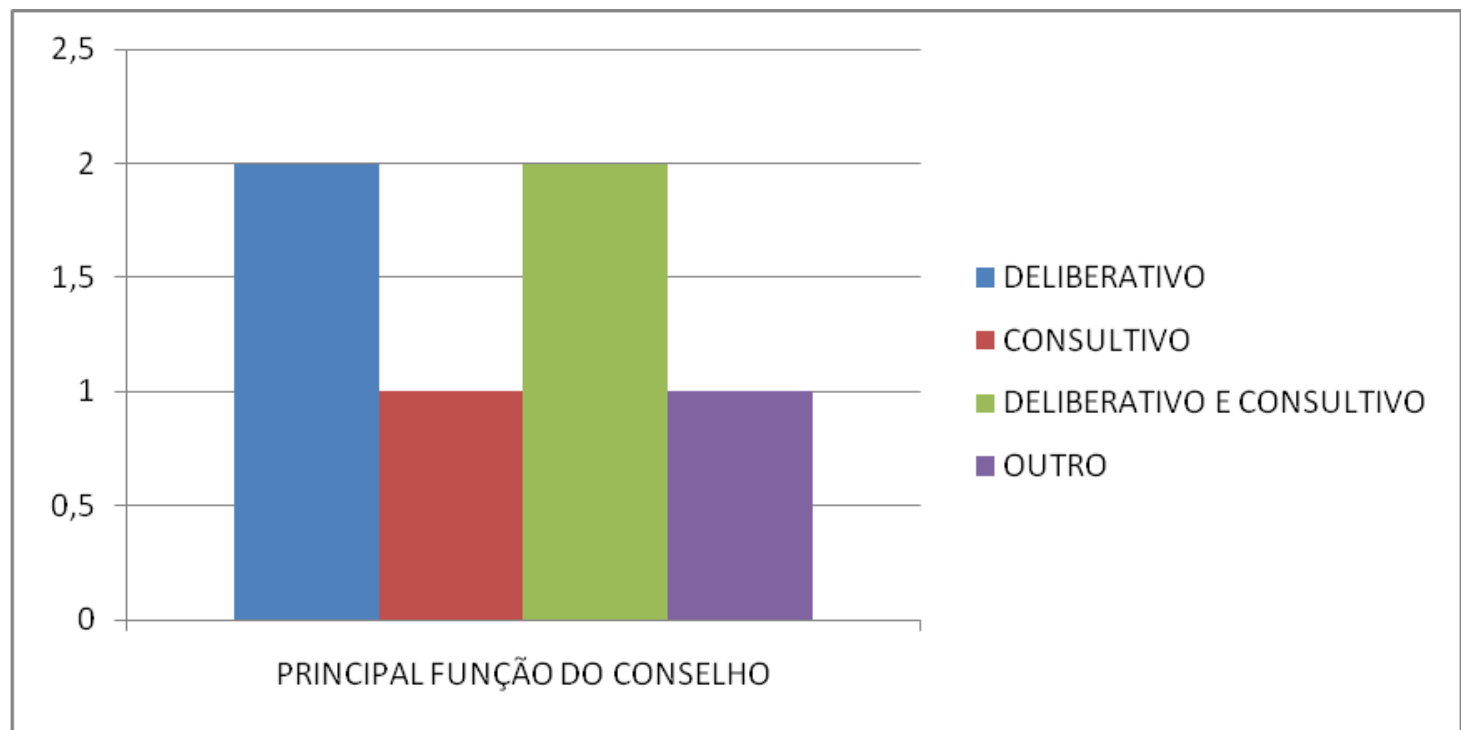

Fonte: Questionário grupo de pesquisa sobre CME/ UFG Regional de Jataí

Os dados acima apontam para as principais características da função do CME nos municípios pesquisados, sendo o destaque para o deliberativo e o consultivo.

O responsável por responder o questionário do município de Mineiros ao destacar a função deliberativa e consultiva, esclarece detalhando as funções do CME, como se lê abaixo:

Baixar normas que regulamenta organização e funcionamento do SME; Deliberar sobre: matérias relativas à autorização, ao credenciamento e autorização, ao reconhecimento de curso e a renovação de reconhecimento das instituições educacionais; emitir parecer sobre: credenciamento e autorização, reconhecimento e renovação de reconhecimento dos cursos 


\title{
Educere Educare \\ ReVISTA DE EduCAC̄̃o
}

Programa de Pós-Graduação em Educação - Universidade Estadual do Oeste do Paraná

\begin{abstract}
das Instituições de Ensino; articular com órgãos Federais, Estaduais e Municipais para acompanhar e fiscalizar a implementação da política educacional no municipio; assessorar em matéria Educacional a Secretaria Municipal de Educação quando solicitado; manter intercâmbio com o CNE, CEE. UNCME e com os demais conselhos municipais; promover encontros, conferências, simpósios e reuniões sobre educação no município; promover a divulgação de estudos sobre a educação no municipio; acompanhar na Câmara Municipal a tramitação de projetos que versem sobre as Políticas Educacionais relativas ao SME; convocar na área de sua competência para eventual prestação de esclarecimentos agentes de educação, integrantes do SME; elaborar proposta de alteração do seu regimento quando entender necessário; encaminhar ao titular da pasta de Educação para conhecimento as decisões do Conselho; acompanhar e fiscalizar a aplicação mínima das receitas resultantes de impostos legalmente vinculados à manutenção e desenvolvimento do ensino no município (QUESTIONÁRIO GRUPO DE PESQUISA DA UFG/JATAİ- CME, 2016).
\end{abstract}

Percebe-se que o $\mathrm{CME}$ do município de Mineiros exerce outras funções destacando-se em relação aos demais. Na letra da lei, aparentemente, aponta para um caminho democrático.

Sob esse viés, compreender as politicas educacionais e a quem elas servem seria um dos papéis do CME, a fim de interagir com o restante da população, com o propósito de conscientizá-la da obrigatoriedade do Estado enquanto mantenedor e responsável por uma educação de qualidade.

Essas observações elucidam que a concretização da gestão democrática não depende somente de planos legais, mas de sujeitos que os implementem. Portanto, cabe aos Conselheiros, além da compreensão técnica, a compreensão política das questões educacionais, e isto depende, também, sobremaneira, da atuação das Secretarias Municipais e dos próprios conselhos, através de uma gestão político-pedagógica, na qual Conselheiros, funcionários e população adquiram a compreensão política do processo educacional. (LIMA, 2001, p. 14).

O municipio de Anápolis destaca sua função deliberativa e consultiva, não se estendendo a nenhum outro elemento que fosse capaz de ampliar o seu papel social, como citado abaixo:

Normatizar o Sistema, Deliberar sobre todas as questões inerentes à Educação Básica do Sistema Municipal de Ensino de Anápolis; autorizar e reconhecer o funcionamento das instituições educacionais componentes do Sistema Municipal de Ensino de Anápolis; aprovar calendários 


\section{Educere Educare \\ RevISTA DE EducAcão}

Programa de Pós-Graduação em Educação - Universidade Estadual do Oeste do Paraná

escolares, Regimentos e matrizes curriculares e outras (QUESTIONÁRIO GRUPO DE PESQUISA DA UFG/JATAİ- CME, 2016).

Para o município de Goianésia, o CME além da função consultiva percebe a importância do $\mathrm{CME}$ em aproximar as politicas públicas do cidadão, como forma de democratização da gestão do ensino, como se lê:

A criação do Conselho Municipal de Educação no município é um importante instrumento para a democratização da gestão do ensino. E é importante em função do seu papel específico de acompanhar as políticas públicas para educação, mas dentro de uma metodologia que aproxime cada vez mais o Conselho da comunidade para que a legislação seja uma mediadora da sociedade que queremos. (QUESTIONÁRIO GRUPO DE PESQUISA DA UFG/JATAİ- CME, 2016).

O respondente de Itumbiara apontou de forma sucinta a principal função do CME, afirmando, apenas, ser deliberativa. As ações em torno do ato de deliberar buscam cumprir a função técnica e o acompanhamento das políticas públicas sobre a educação.

O representante do $\mathrm{CME}$ de Jataí recorreu a alternativa outros, explicando que a principal função do conselho é a garantia da qualidade da educação. Embora não contemple a classificação proposta por Bordignon (2009), a explicação aponta para a essência que as ações do CME deveriam ter, ou seja, oferecer à população a qualidade da educação. No entanto, espera-se que isso não fique somente no âmbito da aparência, mas se efetive em ações verdadeiramente dignas da garantia da qualidade educacional.

Para Lima (2001), um dos papéis essenciais do CME é compreender as políticas educacionais, a fim de interagir com o restante da população, conscientizando-a sobre a obrigatoriedade do Estado enquanto mantenedor e responsável por uma educação de qualidade.

Por sua vez, o municipio de Rio Verde apresenta de forma sucinta as funções deliberativa, consultiva e propositiva. 


\section{Educere "Educare \\ RevISTA DE Educacão}

Programa de Pós-Graduação em Educação - Universidade Estadual do Oeste do Paraná

Diante das respostas percebe-se que cada CME, na sua especificidade, apresenta funções mais burocráticas e técnicas. A busca pela qualidade da educação também se pode encontrar na função técnica, uma vez que se faz necessária a normatizar a educação municipal. Por outro lado, a participação, um indicativo democrático, não fica evidente.

Acredita-se que a participação da sociedade por meio dos CME torna a educação mais justa e/ou mais próxima da igualdade, uma vez que cada membro deverá representar determinada parte da sociedade civil.

Aproximar a população das decisões do poder público é o caminho para que se constitua a educação como forma de ascensão social, por mais que isso não seja o que de fato desejam os governantes.

Desta forma, garantir a democratização educacional é garantir a participação das pessoas no processo e respeitá-las como um ser social, é valorizar a expressão de pensamento e ações em prol da qualidade da educação.

\section{CONSIDERAÇÕES FINAIS}

A implantação e implementação dos Conselhos Municipais de Educação no Brasil não é uma temática nova, mas nos últimos tempos tem se tornado relevante. Entretanto, a questão da participação e da autonomia ainda são categorias carentes de discussões, pois muitas vezes é entendido que a própria constituição do CME por si só já seja democrático.

A análise das respostas do questionário sobre o funcionamento e a atuação do $\mathrm{CME}$, envolvendo os municípios do Estado de Goiás permitiu verificar que a composição dos conselhos, apesar de sua representatividade, nem sempre é de fato democrática. A presença do poder executivo na escolha da composição do colegiado interfere na autonomia das decisões deliberativas do colegiado.

Nesse sentido, encontra-se uma autonomia comprometida, principalmente pela forma de composição do colegiado do CME que tem a ingerência do poder executivo municipal. A autonomia seria possivel ao se articular mecanismos de Revista Educere Et Educare, Vol. 13, N. 27, jan./abr. 2018. Ahead of Print. 


\section{Educere Educare \\ ReVISTA DE EduCACÃo}

Programa de Pós-Graduação em Educação - Universidade Estadual do Oeste do Paraná

eleição, embasados em critérios claros, capazes de gerar princípios democráticos de igualdade e de isonomia. A ideia é garantir a heterogeneidade na composição do conselho.

Por fim, constata-se que, dentre os municípios pesquisados, a visão geral que se tem é a de que muitos municípios ainda possuem conselhos com atuações engessadas. Como afirma Motta (1987), existe uma participação não autêntica. Entretanto, percebe-se que há CME que tenta se sobressair, acredita em seu papel mobilizador, dialogando com a sociedade.

Defende-se que para a democratização da educação é preciso que o CME entenda a importância da participação, elemento que poderá mobilizar o povo a seguir na luta pela qualidade da educação socialmente referenciada

\section{REFERÊNCIAS BIBLIOGRÁFICAS}

ALVES, E. F. Conselhos Municipais de Educação em Goiás: Percurso Legal e desafios para estruturação e funcionamento. Revista Educação e Políticas em Debate, Uberlândia, v. 3, n.2, ago./dez. 2014.

Conselhos Municipais de educação em Goiás: historicidade, movimentos e possibilidades. 2011. 209 f. Dissertação (Mestrado em Educação) Faculdade de Educação. Universidade Federal de Goiás, Goiânia, 2011.

BASÍLIO, P. M. Desafios para a formulação de políticas de educação infantil: um estudo sobre a atuação do Conselho Municipal de Educação de Duque de Caxias. 2012. 200 f. Dissertação (Mestrado em Educação) Programa de PósGraduação em Educação. Centro de Ciências Humanas e Sociais. Universidade Federal do Estado do Rio de Janeiro, Rio de Janeiro, 2012.

BORDENAVE. J. E. D. O que é participação? São Paulo: Editora Brasiliense, 1983.

BORDIGNON, G. Gestão da educação no municipio: Sistema, Conselho e Plano. São Paulo: Ed. Livraria Paulo Freire, 2009.

LIMA, A. B. Conselhos Municipais na Educação: Perspectivas de Democratização da Política Educacional Municipal. 2001. 150 f. Tese (Doutorado em Educação) Programa de Pós-Graduação em Educação. Pontifícia Universidade Católica de São Paulo, São Paulo. 2001. 


\section{Educere Educare \\ REVISTA DE EDUCACÃo}

Programa de Pós-Graduação em Educação - Universidade Estadual do Oeste do Paraná

LIMA, A. B. Conselhos de educação, movimentos sociais e controle social. Revista Educação em Perspectiva, Viçosa, v. 01, n. 1, jan./jun. 2010. Disponivel em: <http://www.seer.ufv.br/seer/educacaoemperspectiva/index.php/ppgeufv/articl e/view/9>. Acesso em: 14 fev. 2017.

. (Org.) PPP: participação, gestão e qualidade de educação. Uberlândia (MG): Assis Editora, 2015.

MOTTA, F. C. P. Administração e Participação: Reflexões para a Educação. In: FISCHMANN, R. (Coord.) Escola Brasileira: temas e estudos. São Paulo: Atlas, 1987.

QUESTIONÁRIO GRUPO DE PESQUiSA DA UFG/JATAİ- CME. Pesquisa Os Conselhos Municipais de Educação em Goiás e a qualidade socialmente referenciada do ensino. UFG/Regional Jataí, 2016.

RAIMANN, A. A gestão e a qualidade da educação. In: LIMA, A.B. (Org.) PPP: participação, gestão e qualidade de educação. Uberlândia (MG): Assis Editora, 2015.

TEIXEIRA, L. H. G. Conselhos Municipais de educação: autonomia e democratização do ensino. Cadernos de Pesquisa. São Paulo, v. 34, n.123, set./dez. 2004. Disponivel em: <http://www.scielo.br/scielo. php?script=sci_arttext\&pid=S0100-

$15742004000300009 \& \operatorname{lng}=$ pt\&nrm=iso\&tlng=pt $>$ Acesso em: 25 set. 2015.

Recebido em: 05/10/2017

Aceito em: 27/02/2018 